Schoten, S.M. van, Groenewegen, P.P., Wagner, C. De ontwikkeling van kwaliteitssystemen in Nederlandse ziekenhuizen tussen 1995 en 2011. TSG: Tijdschrift voor

Gezondheidswetenschappen: 2013, 91(8), 489-496

\begin{tabular}{|l|l|}
$\begin{array}{l}\text { Postprint } \\
\text { Version }\end{array}$ & 1.0 \\
\hline Journal website & http://link.springer.com/article/10.1007\%2Fs12508-013-0160-y \\
\hline Pubmed link & \\
\hline DOI & $10.1007 / s 12508-013-0160-y$ \\
\hline
\end{tabular}

This is a NIVEL certified Post Print, more info at http://www.nivel.eu

\title{
De ontwikkeling van kwaliteitssystemen in Nederlandse ziekenhuizen tussen 1995 en 2011
}

\author{
Steffie M. Schoten, Peter P. Groenewegen, Cordula Wagner
}

\begin{abstract}
This study describes the development of quality systems in Dutch hospitals between 1995 and 2011. To measure the development stage of quality systems, a structured questionnaire was sent to the Board of Directors of all Dutch hospitals in 1995, 2000, 2005, 2007 and 2011. The results of this study show that the development stage of quality systems in Dutch hospitals increased between 1995-2011. In 1995, 52\% of the participating hospitals were in the preparation stage of development. In 2011, 53\% of the participating hospitals already possessed all the necessary elements of a quality system and another $45 \%$ had integrated these elements into a system of continuous quality improvement. Although the development of quality systems increased, this development did not follow the same pattern in the different elements of the quality system. Furthermore, quality systems of larger hospitals were significantly further developed. Future research should focus on further explanations of differences in quality management development stages between hosptitals and the effectiveness of these systems in terms of quality of care.
\end{abstract}

\section{INLEIDING}

Dit artikel beschrijft de ontwikkeling van kwaliteitssystemen in Nederlandse ziekenhuizen tussen 1995 en 2011. In 1996 is in Nederland de Kwaliteitswet Zorginstellingen (KWZ) ingevoerd.1 Deze wet verplicht alle zorginstellingen om de eigen kwaliteit te bewaken, te beheersen en te verbeteren. De KWZ stelt vier eisen aan zorginstellingen: zij dienen verantwoorde zorg te leveren, beleid te hebben dat gericht is op kwaliteit, een kwaliteitssysteem te implementeren en een kwaliteitsjaarverslag op te stellen.2 Als reactie op deze eisen zijn zorginstellingen gestart met het opzetten en implementeren van kwaliteitssystemen. Deze kwaliteitssystemen richten zich op het bewaken van zorgprocessen en de preventie van onbedoelde schade als gevolg van medisch handelen, door het scheppen van randvoorwaarden voor het verbeteren van de kwaliteit van zorg.3,4 In 1995 is de implementatie van kwaliteitssystemen in alle zorgsectoren voor het eerst in kaart gebracht, gevolgd door een meting in 2000.3-6 Uit een vergelijking van de resultaten van beide metingen bleek dat de ontwikkeling niet zo voorspoedig was verlopen als men had gehoopt. Een van de maatregelen die toen is genomen om de 
Schoten, S.M. van, Groenewegen, P.P., Wagner, C. De ontwikkeling van kwaliteitssystemen in Nederlandse ziekenhuizen tussen 1995 en 2011. TSG: Tijdschrift voor

Gezondheidswetenschappen: 2013, 91(8), 489-496

ontwikkeling te versnellen betrof een landelijk actieprogramma voor ziekenhuizen genaamd Sneller Beter. Dit actieprogramma werd op 20 november 2003 gelanceerd op initiatief van het Ministerie van Volksgezondheid, de Orde van Medisch Specialisten, de NVZ vereniging van ziekenhuizen en Verpleegkundigen en Verzorgenden Nederland.7 Het doel van Sneller Beter was om verbeteringen op het gebied van transparantie, doelmatigheid en kwaliteit te stimuleren middels drie pijlers: (1) het creëren van kwaliteitsbewustzijn, (2) het ontwikkelen van een nationale set van indicatoren voor een veilige en betere zorg en (3) het opzetten van het programma Kwaliteit, Innovatie en Doelmatigheid. In totaal hebben 24 ziekenhuizen deelgenomen aan Sneller Beter pijler 3, ingedeeld in drie tranches van acht ziekenhuizen. Elke tranche werd twee jaar lang door een consortium ondersteund bij de uitvoering van het programma.7-9 Gedurende de looptijd van pijler 3 van Sneller Beter, ook wel het implementatieprogramma genoemd, is een aantal tussentijdse evaluaties uitgevoerd.10,11 In 2008 volgde de eind- evaluatie en een onderdeel hiervan was het verschaffen van inzicht in het effect van het implementatieprogramma op de ontwikkeling van kwaliteitssystemen.9,12 Hiertoe is in 2005 en 2007 opnieuw de ontwikkeling van kwaliteitssystemen gemeten volgens dezelfde methode als bij voorgaande metingen.13 Hieruit bleek dat kwaliteitssystemen zich hadden doorontwikkeld en dat deze ontwikkeling sterker was in ziekenhuizen waar Sneller Beter was ingevoerd dan in ziekenhuizen waar dit niet het geval was. Echter de mate van ontwikkeling van het kwaliteitssysteem van de Sneller Beter ziekenhuizen was niet significant hoger dan in de overige, niet-deelnemende, ziekenhuizen.9,12,14 Vervolgens is in 2008 het VMS Veiligheidsprogramma opgezet. Dit programma is een combinatie van een veiligheidsmanagementsysteem en tien inhoudelijke evidence based veiligheidsthema's.15 Het doel van dit programma was tweeledig. Enerzijds moesten alle ziekenhuizen eind 2012 een geaccrediteerd veiligheidsmanagement systeem hebben. Anderzijds dienden alle vastgestelde doelstellingen van de tien veiligheidsthema's te zijn gehaald. Met een veiligheidsmanagementsysteem kunnen ziekenhuizen continu risico's signaleren en verbeteringen doorvoeren en dit wordt daarom gezien als de verankering van patiëntveiligheid.15 Er is een discussie gaande of de effecten van veiligheisinterventies überhaupt wel aan te tonen zijn.16 In het voorjaar van 2013 is het eindrapport over de evaluatie van het VMS rapport verschenen. Hieruit bleek dat de ziekenhuizen op diverse inhoudelijke thema's verbeterd zijn. Sommige thema's, zoals medicatieveiligheid, vragen nog extra aandacht.

In dit artikel kijken we of de ontwikkeling van kwaliteitssystemen is doorgezet ten tijde van het VMS Veiligheidsprogramma. Het doel van dit onderzoek is dan ook te bepalen in hoeverre kwaliteitssystemen in Nederlandse ziekenhuizen zich hebben ontwikkeld sinds de laatste meting in 2007 en hoe deze ontwikkeling zich verhoudt tot de eerdere metingen vanaf 1995. De onderzoeksvraag luidt: Wat is het verloop van de ontwikkeling van kwaliteitssystemen in Nederlandse ziekenhuizen tussen 1995 en 2011?

\section{Kwaliteitssystemen}

Er bestaan verschillende typen kwaliteitssystemen met elk hun eigen invulling, maar kwaliteitssystemen hebben gemeenschappelijk dat zij vrijwel altijd in een bepaalde vorm de volgende vijf domeinen bevatten: Beleid en strategie, Medewerkers, Protocollen en procedures, Cyclische kwaliteitsactiviteiten en Cliënten (in het geval 
Schoten, S.M. van, Groenewegen, P.P., Wagner, C. De ontwikkeling van kwaliteitssystemen in Nederlandse ziekenhuizen tussen 1995 en 2011. TSG: Tijdschrift voor

Gezondheidswetenschappen: 2013, 91(8), 489-496

van ziekenhuizen: Patiënten).4,17 Elk van deze domeinen omvat een aantal activiteiten. De mate van ontwikkeling, ook wel 'volwassenheid' van het kwaliteitssysteem, kan worden herleid uit de mate waarin deze activiteiten systematisch worden uitgevoerd.

In de literatuur worden vier ontwikkelingsfasen van een kwaliteitssysteem onderscheiden.4,17-19,20-22 Allereerst is er Fase 0: 'Oriëntatie en bewustwording'. In deze fase van het kwaliteitssysteem is er nog weinig concreet geregeld maar men begint steeds meer te beseffen dat kwaliteit en de waarborging hiervan belangrijk is. De daaropvolgende fase is de 'Voorbereidende fase' (Fase 1), de eerste stappen in de richting van het opzetten van een kwaliteitssysteem worden in deze fase genomen. Voorzichtig worden er al enkele kwaliteitsverbeterende activiteiten gestart. In Fase 2: 'Procesbeheersing' is de organisatie al een heel eind met het opstellen van beleid, procedures en richtlijnen, met betrekking tot kwaliteit op het gebied van alle onderdelen van het kwaliteitssysteem. Echter, deze onderdelen zijn nog niet geïntegreerd in de bedrijfsprocessen. Dat is wel het geval in de laatste fase 'Samenhang en verankering' (Fase 3) waar niet alleen kwaliteitsverbeterende activiteiten geïntegreerd zijn in de werkprocessen en de dagelijkse praktijk, maar ook beleid systematisch wordt bijgestuurd op basis van kwaliteitsinformatie (een zogenaamde feedback loop). In deze fase is er sprake van een cyclisch proces van continue kwaliteitsverbetering. De laatste fase is het uiteindelijke doel van iedere organisatie, omdat het de hoogste mate van ontwikkeling van het systeem reflecteert en er sprake is van een proces van continue kwaliteitsverbetering.4

\section{Kernpunten}

- Kwaliteitssystemen in Nederlandse ziekenhuizen laten tussen 1995 en 2011 een groei in ontwikkeling zien.

- Bijna de helft van de Nederlandse ziekenhuizen had in 2011 de cyclische fase van kwaliteitsverbetering bereikt, waarin het kwaliteitssysteem is geïntegreerd in dagelijkse werkprocessen en kwaliteit is verankerd in de organisatie.

- Vervolgonderzoek naar verklaringen van verschillen in de ontwikkelingsfase van kwaliteitssystemen tussen ziekenhuizen en de effecten hiervan op de kwaliteit van zorg is van belang.

\section{METHODE}

Om de ontwikkeling van kwaliteitssystemen in Nederlandse ziekenhuizen te bepalen is er in de periode 1995- 2011 een longitudinaal vragenlijstonderzoek uitgevoerd onder alle Nederlandse ziekenhuizen. De metingen vonden plaats in 1995, 2000, 2005, 2007 en 2011.

\section{Respondenten}

De Raden van Bestuur van alle Nederlandse ziekenhuizen zijn benaderd met het verzoek een schriftelijke vragenlijst in te vullen over het kwaliteits- en veiligheidsmanagement in de ziekenhuizen waar zij werkzaam zijn. Eventueel kon de vragenlijst ook ingevuld worden door de kwaliteitsfunctionaris van het ziekenhuis of gezamenlijk. Op de vragenlijst kon men aangeven door wie de vragenlijst werd ingevuld. In onderstaande tabel zijn de responsaantallen en responspercentages per meetjaar weergegeven. De gemiddelde respons over de jaren is $73 \%$. Een verklaring voor de hoge respons is mogelijk het aanbieden van spiegelrapportages waarbij 
Schoten, S.M. van, Groenewegen, P.P., Wagner, C. De ontwikkeling van kwaliteitssystemen in Nederlandse ziekenhuizen tussen 1995 en 2011. TSG: Tijdschrift voor

Gezondheidswetenschappen: 2013, 91(8), 489-496

gegeven antwoorden van een ziekenhuis werden afgezet tegen de antwoorden van de totale groep deelnemende ziekenhuizen. Door fusies is het aantal ziekenhuizen dat is benaderd niet in elk jaar gelijk, het aantal ziekenhuizen in Nederland is over de tijd afgenomen.

\section{[TABEL 1 ]}

\section{Vragenlijst}

De vragenlijst die is gebruikt in dit onderzoek is ontwikkeld en gevalideerd in 19954 en bevat vragen over kwaliteits- en veiligheidsmanagement in ziekenhuizen. Binnen vijf domeinen is gevraagd naar kwaliteitsverbeterende activiteiten die een ziekenhuis ondernam (Zie Tabel 1.). Hierbij zijn de vijf domeinen aangehouden die vrijwel alle kwaliteitssystemen gemeenschappelijk hebben: Beleid en strategie, Medewerkers, Protocollen en procedures, Cyclische kwaliteitsactiviteiten en Patiënten. De vragenlijst is bij elke herhaalde meting in dezelfde vorm ingezet. In het domein 'Beleid en strategie' is gevraagd of het ziekenhuis in het bezit is van bepaalde kwaliteitsdocumenten zoals: missie op schrift, kwaliteitsbeleid op schrift, kwaliteitshandboek. Op de vraag of deze documenten aanwezig waren konden respondenten kiezen uit de antwoordopties 'ja, in bezit', 'in ontwikkeling' en 'nee'. Binnen het domein 'Medewerkers' gaven respondenten aan in hoeverre het personeelsbeleid is gericht op kwaliteitsbeleid. Een voorbeeldvraag is: 'Nieuwe medewerkers worden geschoold in kwaliteitszorg'. De respondenten kruisten hun antwoord aan op een 5- puntsschaal die liep van 'Niet' tot 'Sterk' waarbij 'Sterk' de gewenste situatie weergaf. In het domein 'Protocollen en procedures' werd naar de aanwezigheid van bepaalde protocollen in de organisatie gevraagd, bijvoorbeeld een protocol voor preoperatieve screeningof infectiepreventie. In het domein 'Cyclische kwaliteitsactiviteiten' konden respondenten aangeven of bepaalde activiteiten in hun ziekenhuis plaatsvinden en of de resultaten hiervan aantoonbaar (cyclisch)worden gebruikt voor bijsturing van het beleid. Voorbeelden van cyclische kwaliteitsactiviteiten zijn: incidentenanalyse en interne visitatie. Ten slotte is er in het domein 'Patiënten' aan de respondenten gevraagd in hoeverre patiënten en/of hun belangenorganisaties worden betrokken bij bepaalde kwaliteitsactiviteiten zoals het ontwikkelen van kwaliteitscriteria of patiënt tevredenheidsonderzoeken.4,17,23 De fase indeling is cumulatief, dat wil zeggen dat ziekenhuizen in een bepaalde fase komen wanneer zij ten minste een van de activiteiten van de betreffende fase uitvoeren en vrijwel alle activiteiten uit de onderliggende fases uitvoeren. Daarnaast veronderstelt deze indeling dat elk ziekenhuis in principe in staat zou kunnen zijn om de hoogste fase te bereiken.

\section{Dataverzameling}

Respondenten zijn schriftelijk benaderd met het verzoek de vragenlijst over kwaliteits- en veiligheidsmanagement in te vullen. In een begeleidende brief werd het doel van het onderzoek toegelicht. Na twee en vier weken is een herinneringsbrief verzonden. In ruil voor deelname ontving het ziekenhuis een spiegelrapportage waarin de resultaten van het eigen ziekenhuis werden afgezet tegen de (geanonimiseerde) resultaten van de totale groep deelnemende ziekenhuizen. 
Schoten, S.M. van, Groenewegen, P.P., Wagner, C. De ontwikkeling van kwaliteitssystemen in Nederlandse ziekenhuizen tussen 1995 en 2011. TSG: Tijdschrift voor

Gezondheidswetenschappen: 2013, 91(8), 489-496

\section{Data analyse}

De antwoorden op de vragenlijst zijn gebruikt om kwaliteitsverbeterende activiteiten van ziekenhuizen in kaart te brengen. Op basis hiervan is de ontwikkelingsfase van het kwaliteitssysteem van ziekenhuizen bepaald. Voor elk item uit de vragenlijst is bepaald welke mate van ontwikkeling deze reflecteert, en op basis daarvan is een score toegekend om het item in een ontwikkelingsfase in te delen (zie Tabel 1). Met behulp van beschrijvende statistiek is bepaald hoe de ontwikkeling van kwaliteitssystemen in ziekenhuizen tussen 1995 en 2011 is verlopen. Om te bepalen of er een ontwikkeling in de tijd is in het niveau van de kwaliteitssystemen is een Multi-level analyse uitgevoerd. Multi-level analyse was noodzakelijk door de hiërarchische datastructuur waardoor de verschillende metingen van hetzelfde ziekenhuis niet onafhankelijk van elkaar zijn. Daarnaast was een belangrijke reden om te kiezen voor Multi-level analyse dat deze techniek kan omgaan met een incomplete dataset. Er is in dit onderzoek sprake van een incomplete dataset omdat niet ieder ziekenhuis elk meetjaar heeft meegedaan aan het onderzoek. In een Multi-level model kan hier rekening mee worden gehouden. In de analyse is als volgt omgegaan met fuserende ziekenhuizen. Er deden zich in de onderzoeksperiode twee mogelijke situaties voor: (1) twee of meer ziekenhuizen zijn gefuseerd, (2) een ziekenhuis hield op te bestaan. In het eerste geval kon dit er toe leiden dat er twee ziekenhuizen met hetzelfde indentificatienummer in de data zaten, bijvoorbeeld wanneer beide ziekenhuizen de vragenlijst in de meting na de fusie hadden ingevuld. In dat geval is er een nieuw identificatienummer aangemaakt voor een van de twee ziekenhuizen. In het tweede geval is het ziekenhuis verdwenen als eenheid in de analyse en heeft dit identificatienummer missende waarden voor de resterende onderzoeksperiode.

In de Multi-level analyse is tevens onderzocht of de ontwikkeling van kwaliteitssystemen verschilt voor kleine en grotere ziekenhuizen. Hiervoor is het aantal gerapporteerde formatieplaatsen (fte's- full time equivalents) van de ziekenhuizen als variabele meegenomen in het model. Omdat slechts 54 van de 112 ziekenhuizen (48\%) uit 1995 te identificeren waren is besloten om data uit 1995 niet mee te nemen in de Multi-level analyses. Deze analyses beslaan dan ook alleen de periode 2000-2011 (in de beschrijvende analyses zijn wel alle meetjaren meegenomen). De beschrijvende analyses zijn uitgevoerd met STATA versie 11.0. De Multi-level analyses zijn uitgevoerd met MlwiN versie 2.24.

\section{[FIGUUR 1]}

\section{RESULTATEN}

Figuur 1 laat de ontwikkeling van kwaliteitssystemen tussen 1995 en 2011 zien en hieruit blijkt dat kwaliteitssystemen zich over de jaren heen steeds verder ontwikkeld hebben. In 2011 zijn er vrijwel geen ziekenhuizen meer die zich in de laagste twee fasen van ontwikkeling bevinden (Fase 0 en Fase 1). In 2011 heeft 45\% van alle ziekenhuizen de hoogste fase van ontwikkeling bereikt en 53\% van de ziekenhuizen bevindt zich in de voorlaatste fase van ontwikkeling. In 2007 waren de percentages nog respectievelijk 35\% (Fase 3) en 58\% (Fase 2). De ontwikkeling van kwaliteitssystemen lijkt op het eerste gezicht tussen 2007 en 2011 enigszins af te 
Schoten, S.M. van, Groenewegen, P.P., Wagner, C. De ontwikkeling van kwaliteitssystemen in Nederlandse ziekenhuizen tussen 1995 en 2011. TSG: Tijdschrift voor

Gezondheidswetenschappen: 2013, 91(8), 489-496

vlakken, echter na statistische toetsing bleek dit niet significant te zijn (de resultaten van deze analyse zijn niet opgenomen in de tabellen).

\section{[TABEL 2 ]}

Tabel 2 laat de gemiddelde scores van alle ziekenhuizen zien voor alle vijf domeinen van het kwaliteitssysteem, over de jaren heen. Hier is nogmaals te zien dat kwaliteitssystemen zich steeds verder hebben ontwikkeld in de periode 1995-2011. In 1995 was de gemiddelde ontwikkelingsfase 1,39 (SD 0.62) en in 2011 was de gemiddelde ontwikkelingsfase 2,44 (SD 0,53). Als de ontwikkeling per domein van het kwaliteitssysteem wordt bekeken valt op dat deze niet binnen elk domein op dezelfde manier verloopt. Met name in het domein Patiënten is er sprake van een wisselend patroon. Bij de laatste meting is de gemiddelde score afgenomen van een gemiddelde score van 1.94 (SD 1,05) in 2007 naar een gemiddelde van 1.68 (SD $1,03)$ in 2011.

Tabel 3 laat de resultaten van de Multi-level analyses zien. De eerste kolom bevat het nul model, en geeft de gemiddelde ontwikkelingsfase weer. De random effects laten zien dat er significante verschillen bestaan tussen meetmomenten. In model 1 is de variabele tijd meegenomen en is te zien dat hierdoor de variantie tussen de meetmomenten is afgenomen en dat de variantie tussen ziekenhuizen significant is geworden. De deviance test toont aan dat model 1 significant beter past bij de data dan model $0(\mathrm{P}<0,001)$. Dit betekent dat de verschillen in ontwikkelingsfase over de tijd niet veroorzaakt worden door verschillen in samenstelling van de groep deelnemende ziekenhuizen over de jaren heen maar dat er daadwerkelijk sprake is van een groei in ontwikkelingsfase door de tijd. In de derde kolom zijn de resultaten te zien van model 2 waarin de variabele fte is toegevoegd. Deze variabele geeft het effect van de grootte van de ziekenhuizen (uitgedrukt in fte's) weer. De deviance test toont aan dat model 2 significant beter past bij de data dan model $1(\mathrm{P}<0,001)$. Dit betekent dat grotere ziekenhuizen in een hogere ontwikkelingsfase zitten.

\section{[TABEL 3 ]}

\section{DISCUSSIE}

Het doel van dit onderzoek was in kaart brengen hoe de ontwikkeling van kwaliteitssystemen in Nederlandse ziekenhuizen is verlopen tussen 1995 en 2011. Uit de resultaten van deze studie blijkt dat ziekenhuizen vanaf het eerste meetmoment in 1995 een groei in ontwikkelingsfase van het kwaliteitssystemen hebben doorgemaakt en dat deze groei heeft doorgezet tot en met de laatste meting in 2011. Wanneer deze ontwikkeling wordt uitgesplitst in de verschillende domeinen van het kwaliteitssysteem is te zien dat de ontwikkeling niet in elk domein op dezelfde manier is verlopen. Een opvallende bevinding in dit verband is de terugkerende daling in het domein Patiënten. Patiëntenparticipatie heeft zich de afgelopen decennia sterk ontwikkeld en wordt gezien als een middel om de kwaliteit van zorg te verbeteren.24 Er bestaat een breed scala aan methoden voor patiëntenparticipatie zoals focusgroepen, spiegelgesprekken, deelname aan patiëntenraden en werkgroepen. De hoge mate van institutionalisering van participatie en protoprofessionalisering van patiënten brengen moeilijkheden met zich mee waardoor het lastig is om patiëntenparticipatie om te zetten in een daadwerkelijke bijdrage aan de kwaliteit van zorg.25 De effecten van participatie 
Schoten, S.M. van, Groenewegen, P.P., Wagner, C. De ontwikkeling van kwaliteitssystemen in Nederlandse ziekenhuizen tussen 1995 en 2011. TSG: Tijdschrift voor

Gezondheidswetenschappen: 2013, 91(8), 489-496

zijn dan ook nog onvoldoende aangetoond waardoor er enige terughoudendheid bestaat in het stimuleren van participatie vanuit ziekenhuizen en overheden. 25 Daarnaast is er in het specifieke geval van participatie bij richtlijnontwikkeling een andere moeilijkheid. Richtlijnen in de zorg zijn veelal gebaseerd op Evidence Based Medicine (EBM) en er bestaat een gat tussen deze EBM en patiëntervaringen.25 Het gevaar hierbij bestaat dat ervaringen helemaal niet wordt meegenomen in de uiteindelijke richtlijn omdat het lastig blijkt om de ervaring van patiënten en EBM te integreren.25 Bovenstaande zou een mogelijke verklaring kunnen zijn voor de gevonden scores in het domein Patiënten.

Uit de analyses is tevens gebleken dat de kwaliteitssystemen van grotere ziekenhuizen zich in een hogere fase van ontwikkeling bevinden. Dit is consistent met onderzoek dat pleit voor schaalvergroting van de zorg ten behoeve van een verhoging van de kwaliteit.26-29 Er bestaat echter onduidelijkheid over de effecten van fusies van ziekenhuizen en er is nog onvoldoende overtuigend aangetoond dat fusies tot een verbetering van de kwaliteit van zorg leiden.26-29 In Nederland is het aantal ziekenhuizen teruggedrongen van 143 in 1995 naar 92 in 2012. Deze daling is voor het grootste gedeelte veroorzaakt door fusies wat heeft geleid tot grotere organisaties. De gevonden resultaten in dit onderzoek dragen bij aan de discussie over de effecten van schaalvergroting, en lijken te suggereren dat schaalvergroting wel degelijk een positief effect heeft op de verbetering van kwaliteit middels een ontwikkeld systeem voor continue kwaliteitsverbetering.

Over het algemeen kan men stellen dat de resultaten van dit onderzoek suggereren dat ziekenhuizen moeten blijven investeren in alle afzonderlijke domeinen van het kwaliteitssysteem, ook wanneer er reeds een hoge fase is bereikt. Gebeurt dit niet dan kunnen onderdelen van het kwaliteitssysteem terugvallen naar lagere fases van ontwikkeling. Daarnaast blijkt dat de hoogste fase van ontwikkeling van het kwaliteitssysteem, waarin kwaliteitsverbetering is geïntegreerd in de dagelijkse werkprocessen en beleid systematisch wordt bijgestuurd, moeilijk te bereiken is. Dit kan geconcludeerd worden op basis van het feit dat meer dan de helft (53\%) van de deelnemende ziekenhuizen deze hoogste fase van ontwikkeling nog niet heeft bereikt. Deze ziekenhuizen beschikken weliswaar over alle noodzakelijke onderdelen van een kwaliteitssysteem maar deze onderdelen zijn nog niet geïntegreerd tot een systeem van continue kwaliteitsverbetering.

De resultaten van het huidige onderzoek kunnen worden afgezet tegen Europees onderzoek naar de implementatie van kwaliteitssystemen. Een van de eerste grootschalige Europese projecten was ExPeRT, waarin sterke kanten van ISO, EFQM, peer review en accreditatie zijn onderzocht.30 Vervolgens is het ENQuaL netwerk opgezet als Europees samenwerkingsverband met de nadruk op kennisuitwisseling op het gebied van kwaliteitsmanagement. Binnen ENQual is een vragenlijst ontwikkeld waarmee kwaliteitsmanagement in ziekenhuizen gemeten kan worden.31 In het MARQuiS project is voor het eerst onderzocht wat de toegevoegde waarde van verschillende kwaliteitsverbeterende strategieën in Europese ziekenhuizen is.31 Resultaten lieten zien dat er in alle deelnemende landen ziekenhuizen bestonden met een ver ontwikkeld kwaliteitssysteem maar dat er grote verschillen te zien waren zowel tussen als binnen landen. De variatie binnen landen bleek zelfs vrijwel even groot als de variatie tussen landen.31,32 
Schoten, S.M. van, Groenewegen, P.P., Wagner, C. De ontwikkeling van kwaliteitssystemen in Nederlandse ziekenhuizen tussen 1995 en 2011. TSG: Tijdschrift voor

Gezondheidswetenschappen: 2013, 91(8), 489-496

\section{Beperkingen van het onderzoek}

Een van de mogelijke beperkingen van deze studie is de zelf-rapportage van de Raden van Bestuur en kwaliteitsfunctionarissen. Ziekenhuizen hebben er belang bij om zichzelf goed te presenteren, zeker in huidige tijden waar steeds hogere eisen worden gesteld en er in het kader van transparantie steeds meer data openbaar worden gemaakt. Bovendien kunnen er per ziekenhuis wisselingen binnen de Raad van Bestuur of kwaliteitsfunctionaris zijn geweest, waardoor de antwoorden van een ziekenhuis over de jaren heen niet altijd door dezelfde persoon gegeven zijn. Echter, de brede range in scores, de algehele tendens van verschuivingen naar hogere fases, de anonimiteit van de respondent en het verstrekken van spiegelrapportages ten behoeve van benchmarking, geven aanleiding te veronderstellen dat de vragenlijst in alle eerlijkheid is beantwoord. Een tweede beperking is dat de vragenlijst een beeld geeft van het ziekenhuis als geheel, maar dat er geen inzicht wordt geboden in verschillen tussen en/of binnen afdelingen/onderdelen van het ziekenhuis. Het is echter niet uit te sluiten dat deze verschillen in werkelijkheid bestaan, en bij de interpretatie van de resultaten dient men hiermee rekening te houden.

\section{Vervolgonderzoek}

Vervolgonderzoek zou zich moeten richten op een verklaring voor verschillen in ontwikkelingsfasen van het kwaliteitssysteem tussen ziekenhuizen. Welke factoren of condities dragen bij aan een hoge ontwikkelingsfase, en kunnen ziekenhuizen hier zelf een invloed op uitoefenen? Mogelijke verklaringen kunnen worden gezocht in organisatiekenmerken zoals de complexiteit van de organisatie (bijvoorbeeld verschillen tussen algemene, academische, topklinische en categorale ziekenhuizen) of de aanwezigheid van een fusieverleden. Zoals hierboven reeds besproken is niet aangetoond dat door schaalvergroting de beoogde effecten worden bereikt. De relatief kleine statistische power van het huidige onderzoek liet het echter niet toe om meer variabelen mee te nemen in de analyses.

Naast onderzoek naar mogelijke oorzaken van verschillen tussen ziekenhuizen in de opbouw van het kwaliteitssysteem is het ook belangrijk om aandacht te besteden aan de effecten die deze systemen hebben op de kwaliteit van zorg. Een

kwaliteitssysteem is immers bedoeld om de kwaliteit van zorg te waarborgen en te verbeteren en wordt gezien als een randvoorwaarde voor het garanderen en verbeteren van patiëntuitkomsten. Echter, er is nog nauwelijks onderzoek gedaan naar de effecten van kwaliteitssystemen. Onderzoek dat wel is uitgevoerd is vaak gebaseerd op kleine steekproeven, of richtte zich op één enkele uitkomstmaat, of één enkele organisatie.33 Onderzoek dat wel is uitgevoerd is vaak gebaseerd op kleine steekproeven, of richtte zich op één enkele uitkomstmaat, of één enkele organisatie.33 Weiner en collega's33 waren een van de eersten die een relatie vonden tussen het aantal postoperatieve complicaties en twee maten van patiëntveiligheid: het aantal postoperatieve complicaties en het aantal technische problemen met procedures. Groene en collega's32 vonden een relatie tussen de 'volwassenheid' van een kwaliteitssysteem en een lager aantal ziekenhuiscomplicaties. Het Europese onderzoeksproject DuQuE (Deepening our understanding of Quality Improvement in Europe) kijkt op dit moment onder andere naar de relatie tussen kwaliteitssystemen en de kwaliteit van zorg in Europese ziekenhuizen.34 De resultaten van dit project worden dit jaar verwacht. Vervolgonderzoek zou zich hierbij moeten aansluiten en zich moeten richten op de relatie tussen kwaliteitssystemen en uitkomsten van zorg. 
Schoten, S.M. van, Groenewegen, P.P., Wagner, C. De ontwikkeling van kwaliteitssystemen in Nederlandse ziekenhuizen tussen 1995 en 2011. TSG: Tijdschrift voor

Gezondheidswetenschappen: 2013, 91(8), 489-496

\section{CONCLUSIE}

De ontwikkeling van kwaliteitssystemen in Nederlandse ziekenhuizen laat tussen 1995 en 2011 een groei zien. Bijna de helft van de ziekenhuizen heeft in 2011 de cyclische fase van kwaliteitsverbetering bereikt. Echter, het bereiken van deze laatste fase waarin het kwaliteitssysteem geïntegreerd is in dagelijkse werkprocessen en waarin kwaliteit verankerd is in de organisatie, blijkt voor de andere helft van de ziekenhuizen een moeilijke laatste stap. Deze ziekenhuizen beschikken weliswaar over alle onderdelen van het kwaliteitssysteem maar hebben deze onderdelen nog niet weten te integreren tot een systeem waarin kwaliteitsinformatie via een systematische feedback loop wordt gebruikt om beleid bij te sturen.

\section{LITERATUUR}

1. Kwaliteitswet Zorginstellingen. Den Haag, Ministerie van VWS, 1996.

2. Inspectie voor de Gezondheidszorg, www.igz.nl.

3. Wagner C, Bakker DH de, Sluijs EM. Kwaliteitssystemen in instellingen: de stand van zaken in 1995. Utrecht: NIVEL, 1995.

4. Wagner C. Implementation and effectiveness of quality systems in health care organizations. Utrecht: NIVEL, 1999.

5. Sluijs EM, Wagner C. Kwaliteitssystemen in de zorgsector in 2000. Utrecht: NIVEL, 2000.

6. Sluijs EM, Wagner C. Progress in the implementation of quality management in Dutch health care: 1995-2000. Int J Qual Health Care 2003;15:223-4.

7. Consortium Sneller Beter pijler 3. Landelijk plan van aanpak Sneller Beter pijler 3. Utrecht/Rotterdam/Utrecht: CBO Kwaliteitsinstituut voor de Gezondheidszorg, Instituut Beleid \& Management Gezondheidszorg, Orde van Medisch Specialisten, 2004.

8. Dückers M, Wagner C. Ex ante evaluatie Sneller Beter pijler 3: inventarisatie van de mate waarin de opzet van het programma Sneller Beter pijler 3 voldoet aan eisen ontleend aan literatuur. Utrecht: NIVEL, 2005.

9. Dückers M. Changing Hospital Care. Evaluation of a multilayered organisational development and quality improvement programme. Utrecht: NIVEL, 2009.

10. Dückers M, Bruijn M de, Wagner C. Evaluatie Sneller Beter pijler 3: de implementatie van verbeterprojecten in de eerste acht ziekenhuizen: Utrecht: NIVEL, 2006.

11. Dückers M, Wagner C. Evaluatie Sneller Beter pijler 3: het interne vliegwiel. De stand van zaken in de eerste ziekenhuizen na twee jaar deelname. Utrecht: NIVEL, 2007.

12. Vos L, Dückers M, Wagner C. Evaluatie Sneller Beter pijler 3: resultaten van een verbeterprogramma voor ziekenhuizen. Utrecht: NIVEL, 2008.

13. Sluijs E, Keijser A, Wagner C. Kwaliteitssystemen in zorginstellingen: de stand van zaken in 2005. Utrecht: NIVEL, 2006.

14. Dückers M, Makai P, Vos L, Groenewegen P, Wagner C. Longitudinal analysis on the development of hospital quality management systems in the Netherlands. Int J Qual Health Care 2009;21:330-40.

15. VMS Veiligheidsprogramma, www.vmszorg.nl.

16. Zegers $\mathrm{M}$, Wollersheim $\mathrm{H}$. Landelijk veiligheidsprogramma leidt niet tot halvering van vermijdbare sterfte in ziekenhuizen. Ned Tijdschr Geneesk 2012;156:A4768.

17. Wagner C, Bakker, DH de, Groenewegen PP. A measuring instrument for evaluation of quality systems. Int J Qual Health Care 1999;11:119-30.

18. Crosby PB. Quality is free: the art of making quality certain. New York: MCGraw-Hill, 1997.

19. Hardjono TW, Hes FW. The Dutch Quality Award. Deventer: Kluwer, 1993.

20. Rogers EM. Diffucion of Innovations. New York: The Free Press, 1983.

21. Hage J, Aiken M. Social change in complex organizations. Alphen aan den Rijn: Samsom Publisher, 1980.

22. Mann FC, Neff FW. Managing major change in organizations. Ann Arbor, Michigan:

Foundation for research on human behavior, 1961. 
Schoten, S.M. van, Groenewegen, P.P., Wagner, C. De ontwikkeling van kwaliteitssystemen in Nederlandse ziekenhuizen tussen 1995 en 2011. TSG: Tijdschrift voor

Gezondheidswetenschappen: 2013, 91(8), 489-496

23. Wagner C, Coppen R, Poortvliet MC. Quality and safety management in hospitals (QSMH): survey manual of the QSMH. Utrecht: NIVEL 2006.

24. Bovenkamp HM, Grit K van de, Bal R. Zaakwaarnemers van de patiënt. Rotterdam: iBMG ErasmusMC, 2008.

25. Bovenkamp HM, Grit K van de, Bal R. Inventarisatie patiëntenparticipatie in onderzoek, kwaliteit en beleid. Rotterdam: iBMG ErasmusMc, 2008.

26. Zuiderent-Tjerak T, Kool T, Rademakers J. De relatie tussen volume en kwaliteit van zorg- Tijd voor een brede benadering. Utrecht/Nijmegen/Rotterdam: Consortium Onderzoek Kwaliteit van Zorg, 2012.

27. Medisch-Specialistische Zorg in 20/20- Dichtbij en ver weg. Den Haag: Raad voor de Volksgezondheid en Zorg 2011.

28. Mutter R, Wong H. The Effects of Hospital Competition on Inpatient Quality of Care. Rockville: Agency for Health Care Research and Quality, 2004.

29. Sari N. Do Competition and Managed Care Improve Quality? Health Economics 2002;11:571-584.

30. Shaw C. External quality mechanisms for health care: summary of the ExPeRT project on visitatie, accreditation, EFQM and ISO assessment in European Union countries. Int J Qual Health Care 2000;12:169-75.

31. Lombarts MJMH, Rupp I, Vallejo P, Klazinga NS, Suñol R. Differentiating between hospitals according to the "maturity" of quality improvement systems: a new classification scheme in a sample of European hospitals. Qual Safety Health Care 2009;18:38-43. [CrossRef]

32. Groene O, Mora N, Thompson A, Saez M, Casa M, Suñol R. Is the maturity of hospitals' quality improvement systems associated with measures of quality and patient safety? BMC Health Services Research 2011;11:344.

33. Weiner BJ, Alexander JA, Baker LC, Shortell SM, Becker M. Quality Improvement Implementation and Hospital Performance on Patient Safety Indicators. Med Care Res Rev 2006;63:29.

34. Groene $\mathrm{O}$, Klazinga N, Wagner $\mathrm{C}$ et al. Investigating organizational quality improvement systems, patient empowerment, organizational culture, professional involvement and the quality of care in European hospitals: the 'Deepening our Understanding of Qulaity Improvement in Europe (DUQuE)' project. BMC Health Serv Res 2010;10:281. 
Schoten, S.M. van, Groenewegen, P.P., Wagner, C. De ontwikkeling van kwaliteitssystemen in Nederlandse ziekenhuizen tussen 1995 en 2011. TSG: Tijdschrift voor

Gezondheidswetenschappen: 2013, 91(8), 489-496

\section{TABELLEN EN FIGUREN}

Tabel 1 Kwaliteitverbeterende activiteiten verdeeld over vijf categorieën en vier ontwikkelingsfasen.

\begin{tabular}{|c|c|c|c|c|c|}
\hline & $\begin{array}{l}\text { Beleid en strategie } \\
\text { Beschikt uw zieken- } \\
\text { huis over onder- } \\
\text { staande documenten? }\end{array}$ & $\begin{array}{l}\text { Medewerkers } \\
\text { In welke mate is uw } \\
\text { personeelsbeleid } \\
\text { gericht op kwali- } \\
\text { teitsbeleid? }\end{array}$ & $\begin{array}{l}\text { Protocollen en } \\
\text { procedures } \\
\text { Welke protocollen } \\
\text { worden gebruikt? }\end{array}$ & $\begin{array}{l}\text { Cyclische kwaliteitsactiviteiten } \\
\text { Vinden in uw ziekenhuis } \\
\text { onderstaande activiteiten } \\
\text { plaats? Zo ja, worden de } \\
\text { resultaten aantoonbaar } \\
\text { gebruikt voor bijsturing van } \\
\text { het beleid? }\end{array}$ & $\begin{array}{l}\text { Patiënten } \\
\text { Bij welke kwaliteits- } \\
\text { activiteiten worden } \\
\text { patiënten en/of hun } \\
\text { belangenorganisa- } \\
\text { ties betrokken? }\end{array}$ \\
\hline $\begin{array}{l}\text { Fase o- } \\
\text { Oriëntatie en } \\
\text { bewustwording } \\
\text { Fase } 1 \text { - } \\
\text { Voorbereidende } \\
\text { fase }\end{array}$ & $\begin{array}{ll}\text { - } & \text { missie } \\
- & \text { productomschrij- } \\
& \text { ving } \\
- & \text { kwaliteitsbeleid } \\
- & \text { kwaliteitswerkplan } \\
& \text { instelling } \\
- & \text { kwaliteitsjaarver- } \\
& \text { slag }\end{array}$ & $\begin{array}{ll}\text { - } & \text { stimuleren } \\
& \text { vakinhoudelijke } \\
& \text { ontwikkeling } \\
\text { - } & \text { scholing leiding } \\
\text { - } & \text { scholing mede- } \\
& \text { werkers } \\
\text { - } & \text { deelname in } \\
& \text { werktijd } \\
\text { - } & \text { directie geeft aan }\end{array}$ & $\begin{array}{l}\text { protocollen voor: } \\
-\quad \text { specifieke behan- } \\
\text { deling } \\
-\quad \text { voorlichting } \\
-\quad \text { specifieke doel- } \\
\text { groepen } \\
-\quad \text { voorbehouden } \\
\text { handelingen } \\
-\quad \text { medische hulp- } \\
\text { middelen }\end{array}$ & $\begin{array}{l}\text { - } \text { toetsing monodisciplinair } \\
\text { - toetsing multidisciplinair } \\
\text { - zorgplannen } \\
\text { - commissies } \\
\text { - klachtenregistratie } \\
\text { - cliëntenraad } \\
\text { - functioneringsgesprek }\end{array}$ & $\begin{array}{l}\text { - } \text { patiënt wordt niet } \\
\text { betrokken } \\
\text { patiënt wordt } \\
\text { betrokken bij: } \\
\text { - bespreken van } \\
\text { uitkomsten } \\
\text { - beoordelen of } \\
\text { doelen zijn } \\
\text { gehaald }\end{array}$ \\
\hline $\begin{array}{l}\text { Fase 2- } \\
\text { Proces- } \\
\text { beheersing }\end{array}$ & $\begin{array}{l}\text { - } \text { kwaliteitswerkplan } \\
\text { sommige afdelin- } \\
\text { gen } \\
\text { - } \\
\text { kwaliteitswerkplan } \\
\text { alle afdelingen }\end{array}$ & $\begin{array}{l}\text { - } \text { directie toetst } \\
\text { - } \text { directie bewaakt } \\
\text { - } \\
\quad \text { selectie nieuw } \\
\quad \text { personeel }\end{array}$ & $\begin{array}{l}\text { - } \text { samenwerking } \\
\text { andere instellin- } \\
\text { gen }\end{array}$ & $\begin{array}{l}\text { - } \text { tevredenheidsonderzoek } \\
\text { - behoefteonderzoek } \\
\text { - } \text { management informatie- } \\
\text { systeem } \\
\text { - } \text { inter-institutionele toetsing }\end{array}$ & $\begin{array}{ll}\text { - } & \text { opstellen of } \\
& \text { ontwikkelen } \\
\text { protocollen } \\
\text { - } & \text { opstellen of ont- } \\
& \text { wikkelen criteria }\end{array}$ \\
\hline $\begin{array}{l}\text { Fase } 3^{-} \\
\text {Samenhang en } \\
\text { verankering }\end{array}$ & 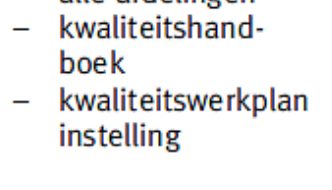 & $\begin{array}{l}\text { - } \text { systematische } \\
\text { selectie en } \\
\text { scholing n.a.v. } \\
\text { prioriteiten in } \\
\text { kwaliteitsbeleid }\end{array}$ & $\begin{array}{l}- \text { routing patiënt } \\
-\quad \text { kritische momen- } \\
\text { ten }\end{array}$ & $\begin{array}{l}\text { - interne audit } \\
\text { - } \text { systematisch tevreden- } \\
\text { heidsonderzoek onder } \\
\text { patiënten }\end{array}$ & $\begin{array}{l}\text { - } \text { participatie in } \\
\text { commissies of in } \\
\text { verbetertrajecten }\end{array}$ \\
\hline
\end{tabular}

(aangepaste versie Sluijs \& Wagner, 2000) 
Schoten, S.M. van, Groenewegen, P.P., Wagner, C. De ontwikkeling van kwaliteitssystemen in Nederlandse ziekenhuizen tussen 1995 en 2011. TSG: Tijdschrift voor

Gezondheidswetenschappen: 2013, 91(8), 489-496

Figuur 1. De ontwikkeling van kwaliteitssystemen in Nederlandse ziekenhuizen tussen 1995 en 2011.

Fase $0=$ Oriëntatie en bewustwording; Fase $1=$ Voorbereidende fase; Fase 2= Procesbeheersing; Fase 3= Samenhang en verankering.

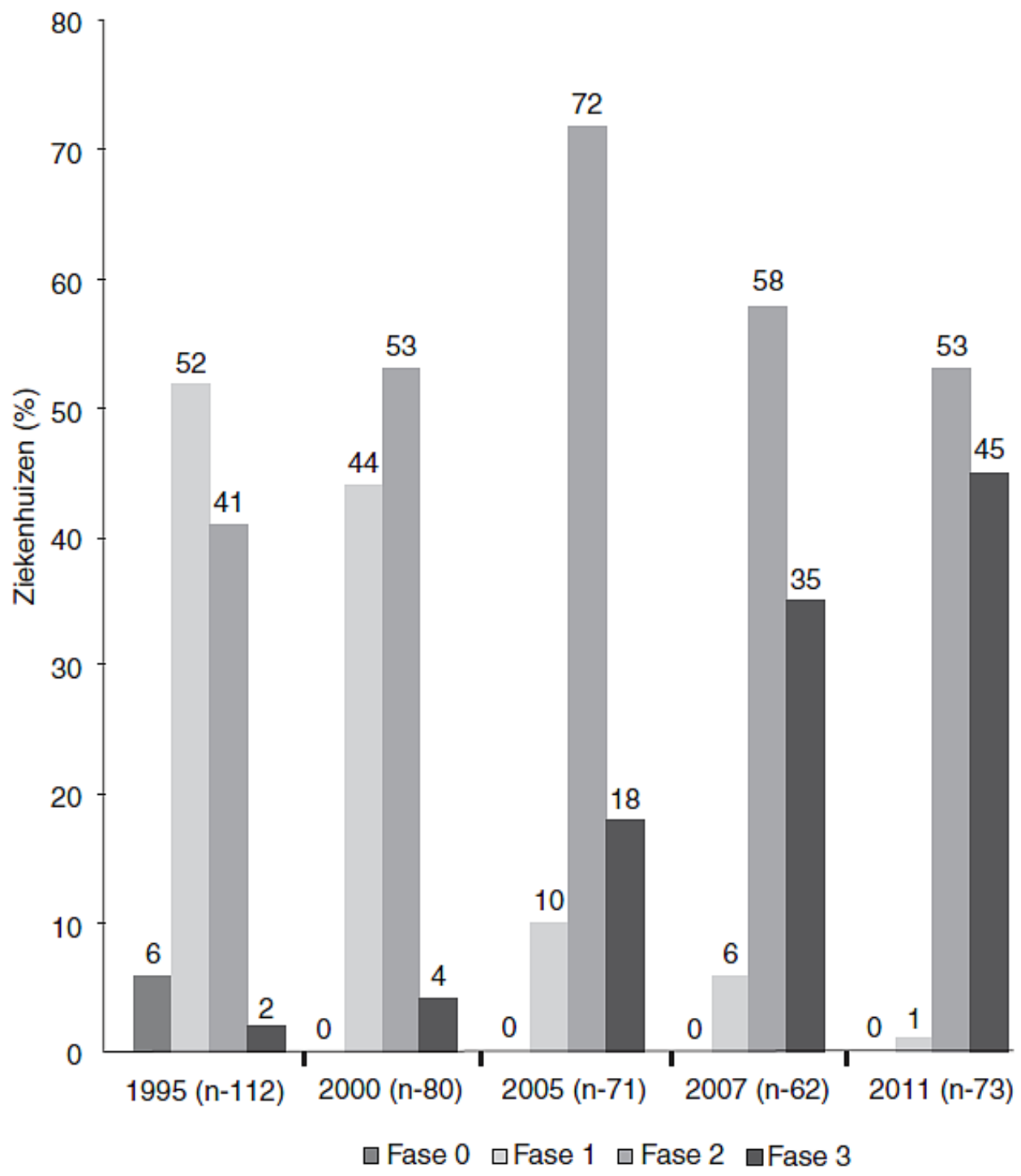


Schoten, S.M. van, Groenewegen, P.P., Wagner, C. De ontwikkeling van kwaliteitssystemen in Nederlandse ziekenhuizen tussen 1995 en 2011. TSG: Tijdschrift voor

Gezondheidswetenschappen: 2013, 91(8), 489-496

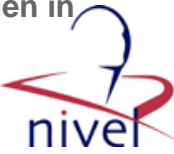

Tabel 2 Gemiddelde score voor de ontwikkelingsfase van het kwaliteitssysteem en gemiddelde scores op onderdelen van het kwaliteitssysteem tussen 1995 en 2011.

\begin{tabular}{|c|c|c|c|c|c|c|c|c|c|c|c|c|c|c|c|}
\hline \multirow[b]{2}{*}{ Onderdeel } & \multicolumn{3}{|c|}{$1995(n=112)$} & \multicolumn{3}{|c|}{$2000(n=80)$} & \multicolumn{3}{|c|}{$2005(n=71)$} & \multicolumn{3}{|c|}{$2007(n=62)$} & \multicolumn{3}{|c|}{$2011(n=73)$} \\
\hline & Gem & SD & Range & Gem & SD & Range & Gem & SD & Range & Gem & SD & Range & Gem & SD & Range \\
\hline Beleid en strategie & 1,53 & 0,64 & $0,00-2,00$ & 1,73 & 0,64 & $0,00-3,00$ & 2,15 & 0,47 & $0,00-3,00$ & 2,40 & 0,49 & $2,00-3,00$ & 2,48 & 0,53 & $1,00-3,00$ \\
\hline Medewerkers & 1,72 & 0,84 & $0,00-3,00$ & 1,30 & 0,58 & $1,00-3,00$ & 2,56 & 0,58 & $1,00-3,00$ & 2,53 & 0,53 & $1,00-3,00$ & 2,67 & 0,55 & $1,00 \cdot 3,00$ \\
\hline $\begin{array}{l}\text { Protocollen en } \\
\text { procedures }\end{array}$ & 1,81 & 0,84 & $0,00-3,00$ & 2,10 & 0,67 & $1,00-3,00$ & 2,30 & 0,68 & $1,00-3,00$ & 2,53 & 0,65 & $1,00-3,00$ & 2,62 & 0,59 & $1,00-3,00$ \\
\hline $\begin{array}{l}\text { Cyclische kwali- } \\
\text { teitsactiviteiten }\end{array}$ & $1,00^{a}$ & 0,00 & $1,00-1,00$ & 2,05 & 0,35 & $0,00-3,00$ & 1,72 & 0,86 & $1,00-3,00$ & 1,98 & 0,97 & $0,00-3,00$ & 2,39 & 0,88 & $1,00-3,00$ \\
\hline Patiënten & 1,53 & 1,06 & $0,00-3,00$ & 1,28 & 1,23 & $0,00-3,00$ & 1,62 & 1,10 & $0,00-3,00$ & 1,94 & 1,05 & $2,00-3,00$ & 1,68 & 1,03 & $0,00-3,00$ \\
\hline Fase $^{b}$ & 1,39 & 0,62 & $0,00-3,00$ & 1,60 & 0,56 & $1,00-3,00$ & 2,08 & 0,53 & $1,00-3,00$ & 2,29 & 0,58 & $1,00-3,00$ & 2,44 & 0,53 & $1,00-3,00$ \\
\hline
\end{tabular}

${ }^{a}$ missing ${ }^{b} 0=$ Oriëntatie en bewustwording; $1=$ Voorbereidende fase; $2=$ Procesbeheersing; $3=$ Samenhang en verankering.

Tabel 3 Multi-level analyse van het effect van tijd en type ziekenhuis op de ontwikkelingsfase van kwaliteitssystemen tussen 2000 en 2011

\begin{tabular}{|c|c|c|c|}
\hline & $\begin{array}{c}\text { Model o } \\
\text { (leeg model) } \\
\mathbf{n = 2 8 4}\end{array}$ & $\begin{array}{c}\text { Model } 1 \\
\text { (model } 0+\text { tijd) } \\
n=284\end{array}$ & $\begin{array}{c}\text { Model } 2 \\
\text { (model } 1+\text { fte) } \\
n=270\end{array}$ \\
\hline Fixed effects & B coefficient (SE) & B coefficient (SE) & B coefficient (SE) \\
\hline Ontwikkelingsfase van het Kwaliteitssysteem intercept (constant) & $2,084(0,033)^{* * *}$ & $1,728(0,045)^{\star \star \star}$ & $1,657(0,051)^{\star \star * \star}$ \\
\hline Tijd (2000-2011) & - & $0,064(0,006)^{\star \star *}$ & $0,062(0,006)^{\star * \star}$ \\
\hline fte (fte $\times 1000)$ & - & - & $0,052(0,017)^{* *}$ \\
\hline \multicolumn{4}{|l|}{$\begin{array}{l}\text { Random effects } \\
\text { Variantie componenten: }\end{array}$} \\
\hline \multicolumn{4}{|l|}{ Variantie componenten: } \\
\hline - ziekenhuis (level 2) & $0,023(0,017)$ & $0,039(0,014)^{\star *}$ & $0,029(0,013)^{*}$ \\
\hline - meetmoment (level 1) & $0,241(0,025)^{\star \star *}$ & $0,154(0,016)^{\star * \star}$ & $0,158(0,017)^{* \star *}$ \\
\hline -2loglikelihood (IGLS) & 425,534 (ref) & 328,086 & 306,727 \\
\hline Deviance test & Referentie & $\mathrm{P}<0,001$ & $\mathrm{P}<0,001$ \\
\hline
\end{tabular}

${ }^{*} \mathrm{P}<0,05,{ }^{* *} \mathrm{P}<0,01,{ }^{* * *} \mathrm{P}<0,001$ 